\title{
EDITORIAL
}

\section{MODERN BUILDING MATERIALS AND THEIR INVESTIGATION METHODS}

\author{
Albinas Gailius ${ }^{1}$, John Kinuthia ${ }^{2}$ \\ Guest Editors \\ ${ }^{1}$ Faculty of Civil Engineering, Vilnius Gediminas Technical University, Sauletekio al. 11, \\ LT-10223 Vilnius, Lithuania \\ ${ }^{2}$ Faculty of Advanced Technology, University of Glamorgan, Llantwit Road, Trefforest, \\ Pontypridd, Mid Glamorgan, Wales, United Kingdom, CF37 1DL \\ E-mail:1'albinas.gailius@st.vgtu.lt; ${ }^{2}$ jmkinuth@glam.ac.uk
}

This special issue is dedicated to research problems in the field of building materials and their technologies.

The journal gives the priority to preparing the issues focussed on some particular topics. Sometims they are based on the material of recent conferences. For example, such an issue has been published by professors Mang and Kaklauskas (2009). It was after the 9th International Conference on Modern Building Materials, Structures and Techniques, in Vilnius, May 16-18, 2007.

The first conference was held in 1991. At the last conference, with a participation of 458 researchers from 25 countries, 193 oral presentations (including key-note lectures) were given and 58 posters were discused. The conference series provides an excellent international forum for discussion and debate, highlighting advances in theoretical, technological and experimental research, aimed at solving challenging problems of Materials, Structures and Techniques.

The conferences have been organised jointly by the Civil Engineering Faculty of Vilnius Gediminas Technical University (VGTU) and the Lithuanian Academy of Sciences. The International Association for Bridge and Structural Engineering as well as the Board of the Association of European Civil Engineering Faculties and European Council of Civil Engineers are the official sponsors of the Conference.

Professor E. K. Zavadskas, Editor-in-Chief of the Journal of Civil Engineering and Management, kindly invited us to edit a special issue for this Journal in the research field of Building Materials. We gladly accepted this invitation, because Journal publishing original publications in this field. For example, Owsiak (2007), etc.

We agreed that we should invite internationally known researches. The submitted papers underwent a rigorous international peer review procedure. The objective was to produce an issue containing outstanding quality papers. The critical comments of the reviewers were highly appreciated.
The first paper, authored by J. Bai and A. Gailius, is aimed to develop high-performance Portland cement (PC), fly ash (FA) and metakaolin (MK) concrete have been developed in wide applications, it has growing interest in optimizing and predicting consistency of fresh PC-FA-MK concrete for efficient and practical design and construction. This paper presents statistical models for predicting the consistency of concrete incorporating $\mathrm{PC}, \mathrm{FA}$ and $\mathrm{MK}$ from the experimental results of standard consistency tests.

The paper presented by J. Szwabowski and Łaźniewska-Piekarczyk deals to the actual state of knowledge and in accordance with the PN-EN 2006-1 norm, it is recommended to use air-entrainment as a basic way of assuring frost-resistance of concrete. In the paper, the problem of air-entrainment is discussed, formed as a result of the functioning of a superplasticizer on the characteristics both of concrete and a mixture, depending on the content.

The third paper by J. Kinuthia at al. investigates the way in which colliery spoil can be utilized in lowstrength concrete. Colliery Spoil (CS) (minestone), a byproduct of coal mining, is abundant in most parts of the world. It has potential as a construction material has not been fully appreciated. Results indicate that the performance of systems incorporating CS and WSA were of very poor workability, but the resultant strength was within the low-to medium category usable for blinding concrete .

In M. Jaśniok and A. Zybura paper presented the model of carbonated concrete realkalization is compiled on the basis of the multi-component medium theory equations. The experimental testing reported is related to a theoretical model which determines changes of ion concentrations in the pore solution of the cover, as a result of the realkalization.

The fifth paper, authored by H. Sivilevičius and Š. Šukevičius deals with technological schemes of ma- 
king hot-mix asphalt (HMA) mixture used in Lithuania and other countries. The data obtained were analysed and compared to the output of HMA mixtures in other countries and the dynamics of the development of AMP models used in Lithuania and changes in their numbers were determined.

J. Gołaszewski investigated the influence of Viscosity Enhancing Agents (VEA) on the rheological properties of mortars, different in cement and superplasticizer properties, are presented and discussed. Rheological parameters were measured using Two-Point Workability Test (TPWT).

E. Raue et al. presented experimental results of tension member tests are used as a basis from which to develop an extended tension stiffening model for reinforced concrete, with emphasis on the specific concrete damage and the developments of residual deformations depending on the structural loading.

The eighth paper, authored by R. Mačiulaitis and J. Malaiškiené, presented, how the selected stages of drying regime influence the structural parameters of ceramics (reserve of porous volume, heterogeneity degree of structure, maximum rate of capillary rise according to watering front.

In the last paper, S. Gaidučis et al.deals with one of the most economically perspective technogenic waste extractive hemihydrate phosphogypsum was investigated. Products made from reprocessingextractive hemihydrate phosphogypsum can replace other energy consuming articles for wall partitions. Ageing dihydrate formed during the aging reduce the induction and nucleation period.

We wish to thank the authors of the papers for their efforts concerning preparation and revision of the manuscripts.

\section{References}

Mang, H. A.; Kaklauskas, G. 2009. Editorial, Journal of Civil Engineering and Management 15(1): 5-6.

Owsiak, Z. 2007. Testing alkali-reactivity of selected concrete aggregates, Journal of Civil Engineering and Management 13(3): 201-208. 